International Journal of Linguistics, Literature and Culture
Available online at https://sloap.org/journals/index.php/ijllc/
Vol. 6, No. 6, November 2020, pages: 24-35
$\begin{aligned} & \text { ISSN: 2455-8028 } \\ & \text { https://doi.org/10.21744/ijllc.v6n6.1009 }\end{aligned}$

\title{
Disagreement: A Speech Act Analysis and Classroom Implications
}

Panha Song a

Article history:

Submitted: 27 August 2020

Revised: 18 September 2020

Accepted: 09 October 2020

\section{Keywords:}

disagreement;

English as a foreign language;

politeness strategies;

pragmatic competence;

speech acts;

\begin{abstract}
The disagreement has been widely regarded as one of the most interesting speech acts in the EFL context since the way the speaker expresses her or his opposing view can affect the addressee's self-image and view of the addressor. This article attempted to identify various strategies native speakers of English realize this speech act through a qualitative method by analyzing two sets of authentic data from two half-hour interviews. Next, the article investigated the lack of emphasis on disagreement in EFL materials before offering possible suggestions to equip non-native learners of English with pragmatic competence to disagree appropriately. The findings and recommendations had implications for EFL teachers and course developers in how and why speech acts and pragmatic competence should be emphasized to ensure that non-native speakers of English could communicate effectively without being perceived as socially and pragmatically inferior.
\end{abstract}

International journal of linguistics, literature and culture () 2020.

This is an open access article under the CC BY-NC-ND license (https://creativecommons.org/licenses/by-nc-nd/4.0/).

\section{Corresponding author:}

Panha Song,

Department of English, The Royal University of Phnom Penh

Phnom Penh, Cambodia.

Email address: panha.song@rupp.edu.kh

\footnotetext{
${ }^{a}$ Department of English, The Royal University of Phnom Penh, Cambodia
} 


\section{Introduction}

\section{Pragmatics and speech acts in the EFL context}

Within the realm of pragmatics, Austin's (1962), development of the speech-act theory in How to Do Things with Words has arguably revolutionized the way we look at language forever. Austin, opposing to the philosophical focus of language at the time, suggests that language can serve more than just to make factual statements or assertions. Through language, people can perform actions such as making promises, expressing agreement, giving warnings and more. This theory also allows us to see the connection between an utterance's propositional or literal meaning and illocutionary or intended meaning (Paltridge, 2012). If, for example, someone produces the utterance 'This room is so cold.', the propositional meaning will be the person's mere comment on the temperature of the room while his or her intention could be a request for someone to turn on the heater or a complaint about the excessive cold in the room. Unfortunately, the example above also shows us that it is quite challenging, especially for EFL learners, to assign utterances to certain speech act categories (e.g. whether it is a request or a complaint or both) since it involves the interlocutors' thorough understanding of context, language forms and functions due to the indirectness of the speech act. In other words, while it is easier for learners to notice a speech act through the straightforward relationship between the illocutionary force and the utterance (direct speech act) such as 'I request you to turn on the heater.', they tend to encounter problems when the underlying force and form of the utterance are expressed implicitly (indirect speech act) (Flowerdew, 2012). For instance, they might not be familiar with certain structures that are related to typical illocutionary force in the conventionalized speech act and treat 'Can you turn on the heater?' as a genuine question of ability and reply with a simple 'Yes, I can.' before walking away. Likewise, nonconventional indirect speech acts, which require context for their interpretation, can also pose problems for learners as they might just miss the fact that the utterance 'This room is so cold.' produced by their guest is an indirect request and choose not to react to it.

The problematic nature of pragmatics and speech acts in the ELT context has been discussed by many researchers. Bardovi-Harlig \& Hartford (1990), have found that language learners, regardless of their proficiency level, still lack the pragmatic competence to communicate effectively, which could cause a serious communication breakdown between non-native speakers and their native counterparts. A similar finding from the study on adult foreign and second language learners from Bardovi-Harlig \& Dörnyei (1997), also confirms that a learner's pragmatic competence does not coincide with his or her grammar enrichment; thus, even nonnative learners whose English is fluent may still struggle to communicate their pragmatic intention in a proper way. While linguistic errors may suggest that it is merely a part of the speakers' limited knowledge about the language, failure to show pragmatic competence might project the impression that the speaker is offensive. One of the possible explanations for these difficulties, which will be discussed by the present analysis, is derived from learners' misunderstanding of the target language due to the materials to which they are exposed in their classrooms. As the need to communicate effectively in English becomes more crucial than ever, many global textbooks have been published to contribute to learners' quest to become an able language user. However, a deeper investigation into these world-renowned textbooks reveals that there can be a gap between what is presented in those materials and what learners need to achieve pragmatic competence. For example, Ren \& Han's (2016) empirical study of ten English language textbooks used in Chinese universities shows that there is insufficient contextual information provided to learners since most of the examined textbooks only supply isolated fixed phrases considered useful for achieving the communicative purpose or speech act. Likewise, Vallenga's (2004), the study of eight global EFL textbooks has shown that the number of speech acts found in the examined data is still seriously under-represented and the tendency to explicitly link certain speech acts to specific linguistic structures (e.g. using won't for making refusal) without stating that there are other alternatives to achieve the same speech act could give learners the false impression that there are no other ways to achieve the illocutionary force, which can make them a less capable speaker.

\section{Politeness strategies and face management}

In chapter 6 of his Meaning in interaction: An introduction to pragmatics, Thomas (2014) describes the significance and elements of the politeness theory that are of interest to pragmatists. Subscribing to his description, the present analysis only considers politeness as a pragmatic concern when the speaker deliberately utilizes various strategies to achieve specific goals; hence, the phenomenon where the speaker has no choice but to be polite according to external

Song, P. (2020). Disagreement: a speech act analysis and classroom implications. International Journal of Linguistics, Literature and Culture, 6(6), 24-35. https://doi.org/10.21744/ijllc.v6n6.1009 
factors such as the addressees' superior status or the situational demand for formality (deference and register) are beyond the discussion. One of the most prominent works in the politeness theory was produced by Brown \& Levinson (1987), as it helps describe the strategies speakers adopt to avoid impeding the other person's need to be free from imposition when pursuing his or her goals (negative face) or the desire to be liked by others (positive face). Figure 1 serves as an illustration for the super strategies deployed by the speaker when performing speech acts that could harm another person's face or image as a social member.

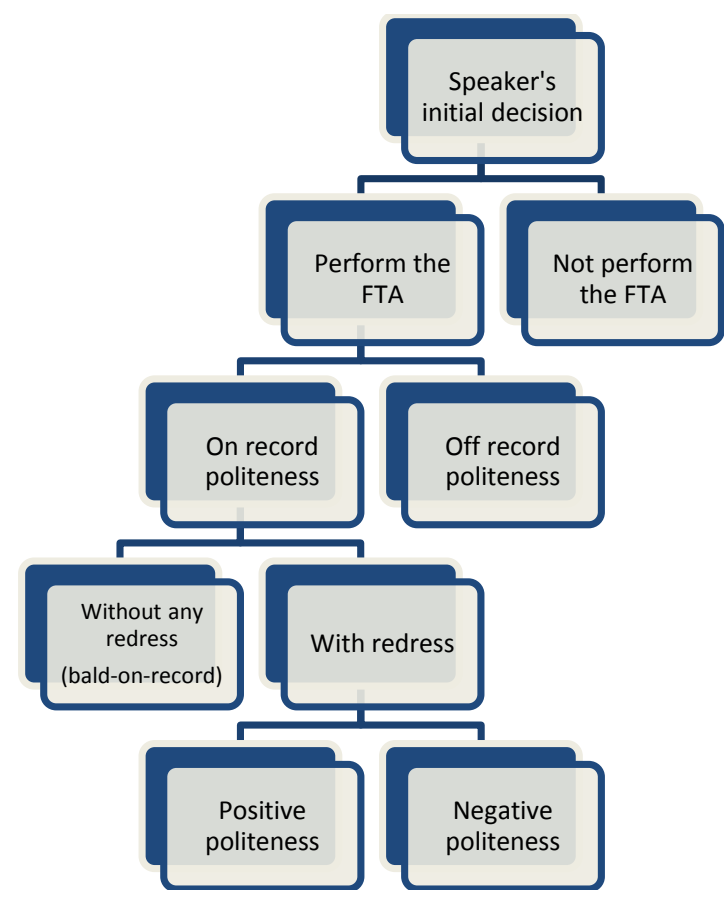

Figure 1. Speaker's Superstrategies for Performing Face-threatening Act (FTA) (Adapted from Brown \& Levinson, 1987)

\section{The speech act of disagreement}

According to Brown and Levinson (ibid.), certain illocutionary acts are inherently inclined to threaten another person's face. A prime example of such a speech act is disagreement. As Malamed (2010), suggests, due to its nature to hinder the bond between the speaker and the addressee, nonnative speakers often struggle to appropriately express opposing opinions in the target language. Also, studies show that the interactors' status, intensity level, and context can also be the deciding factors for how to disagree in the right way (Rees-Miller, 2000; Angouri \& Locher, 2012). Leech's (1983), Agreement Maxim explains that people tend to be less direct when expressing disagreement as the maxim dictates that they need to "minimize disagreement and maximize agreement between self and other". Thus, in the EFL context, learners need to add the much-needed awareness of the linguistic means used to achieve the pragmatic aim (pragmalinguistics) and the relationship between social aspects and pragmatics (sociopragmatics) to their communicative repertoire if they wish to disagree effectively without being considered offensive.

However, before embarking on the analysis of the data, a sufficient definition of the speech act in question is needed to delimit what should be regarded as a realization of disagreement. In Kakava's (2002), study of opposition in modern Greek discourse, a disagreement is defined as "the negation of a stated or implied proposition; in other words, it will always occupy the second conversational turn of an adjacency pair". From this definition, it can be interpreted that disagreement is a unique speech act in that it is a responding move to a previous utterance. Simply put, for the analysis, the speech act of disagreement is realized: 
When the speaker notices that the statement made or implied by the addressee contradicts what he or she believes and produces an utterance in response that either directly or indirectly means the opposite to what was uttered by the addressee.

The definition limits disagreement to an utterance level since the focus of the analysis is a verbal representation of disagreement; thus, nonverbal ways of disagreeing, although possible, are discarded. The definition also disregards any opposing expressions that exceed beyond two turns to distinguish between a disagreement and an argument, which tends to take longer turns and need more elaborate support. Also, the fact that disagreement does not require formal linguistic conventions makes this speech act differently from that of a debate. Finally, the definition also suggests that only the speaker believes that the utterance made by the addressee is not true, so disagreement is different from a tease in which both the speaker and the addressee are fully aware of the fact that the utterance is false.

About the politeness strategies, an interesting finding by Rees-Miller (ibid.) needs to be discussed for further clarification of the scope of the analysis. In his observational research on disagreement in an American academic setting, he has found that disagreements between professors and students are an effective learning tool and should be seen as a face-enhancing act since it shows that the students are fully immersed in the session. Nonetheless, the present analysis does not carry the intention to focus on such a specific context. Rather, the concentration is on certain utterances of disagreement that could pose some degrees of threat to the addressee's face to describe the strategies and reasons behind any notable discovery.

\section{Materials and Methods}

\section{Data collection}

In this analysis, the two sets of data were collected from two half-hour interview settings (see Appendix 1). The first set of data is an interview from the show Off the Record between the host, Michael Landsberg, and Phil Brooks, also known as CM Punk, who is a former professional wrestler and is currently signed with the Ultimate Fighting Championship. The interview covers various topics such as Brooks' former career as a wrestler and his future opponent in the UFC. The second set of data is from an interview from Larry King Now between renowned television personality Larry King and John Cena, a professional wrestler. The topics covered are the differences between wrestling and other sports as well as the potential return of a former professional wrestler, Hulk Hogan.

The reason why interview settings were preferred to more scripted forms of entertainment such as soap operas or sitcoms is due to their authenticity and spontaneity. In real interview settings, disagreement often occurs naturally from the context without any particular predetermined intention; thus, the corpus could provide a realistic representation of how people realize their aim to oppose others' views in the most authentic way possible. Similarly, the participants who are involved in the speech act are also liable to suffer actual consequences such as damaging each other's faces in this type of environment. As the interviews happened in real-time, the methods utilized by the speakers when they disagree with the addressee's proposition could be beneficial for the aim to describe how people maintain politeness and face under these unplanned circumstances.

\section{Strategies for realizing disagreement}

Between the two sets of data, the analysis has found twelve situations where the speaker either tries to respond to the addressee's utterance to directly or indirectly indicate that what the addressee uttered was not true. Using those occurrences, the following strategies along with examples have been proposed to show how disagreement is realized in such context.

1) Using absolute or unmitigated disagreement. (e.g. No, you're not gonna fight me.).

2) Using hesitation sounds or words (e.g. well, uh, err) as a preface to the disagreement. These tend to act as a preceding marker for disagreement. (e.g. Well, I don't have an agenda.).

3) Using a question as a form of disagreement. (e.g. Wouldn't you agree that this is different?)

4) Using words to express slight agreement (e.g. right, sure) before but to partially acknowledge the addressee's proposition before objecting. (e.g. Sure but you know my integrity is pretty powerful as well.).

Song, P. (2020). Disagreement: a speech act analysis and classroom implications. International Journal of 
5) Using humour to weaken the severity of the disagreement, but the addressee can notice it as an objection. (e.g. I will believe it when I see it.).

6) Providing a personal or emotional reason to avert being extremely disagreeable. (e.g. I think I would look at it like a baseball team.).

7) Using modal verbs (e.g. may, might, could) to express partial agreement before using but to express an opposing view. (e.g. Certain players may be more popular than others, but you need to feel the team to win.)

8) Repeating (some part of) the addressee's proposition to challenge it. (e.g. Making a joke of it?).

9) Placing responsibility in a more general context rather than being solely responsible for the opposing opinion (e.g. (it) depends on who you ask.).

The strategies above are created to show the various ways people use to disagree with what they believe to be untrue. However, it is worth mentioning that the speaker sometimes adopts multiple strategies to achieve the speech act.

Uh...we...we have a very strong brand and I think um...I would look at it like a baseball team. There's a bunch of players on that team and certain players may be more popular than others, but you need to feel the team to win. (using hesitation sounds, giving personal reasons, using modals as partial agreement before 'but')

\section{Politeness strategies in performing disagreement}

As discussed above, Leech's (ibid.) Agree Maxim believes that people are less overt when they disagree with one another. To some extent, the result in the corpus seems to support his principle since there are instances where the speakers appear to orient toward the addressee's negative face by using questions (Wouldn't you agree that this is different?), personal reasons (I think I would look at it like a baseball team.), modals as downtoners (Certain players may be more popular than others), or words of uncertainty ((it) depends on who you ask.). Similarly, the speakers also soften their disagreement by using strategies for positive politeness such as using humor (I will believe it when I see it), the inclusion of the addressee and partial agreement (Sure but you know my integrity is pretty powerful as well.). However, it is noticeable, despite Leech's maxim, to see there are occurrences where the speaker decides to use aggravated disagreement or bald-on-record face-threatening acts by using rhetorical questions (Making a joke of it?), obvious disagreement (Not a goody-two-shoes.), or even intensifying the disagreement by directly negating the addressee's proposition (Well, I don't have an agenda.).

The existence of direct disagreement in the present corpus poses a question about the underlying motion behind occasions where speakers decide to use bald-on-record face-threatening acts. A possible explanation for this phenomenon is related to the significance of the topic. LoCastro (1986), conducts a comparative study about disagreements between American English and Japanese speakers, and he has found that direct disagreement certainly appears in both groups of respondents when the topic of discussion is of minimal importance such as questions about food taste. Comparing this topic to the ones with greater importance, namely an interview where a student frantically seeks ways to weaken the level of disagreement while he expresses his feelings about testing to his teacher by Salsbury \& Bardovi-Harlig (2000), it shows that disagreeing with a teacher about a high-stakes topic is more significant and requires more careful language use than expressing opposing opinions about food. The corpus also suggests a similar explanation as John Cena, in sample 11, does not refrain from directly disagreeing with the interviewer's proposition since the topic is simply about him being portrayed as an all-good American in the ring. However, as the topic becomes more important, as in sample 3 where the interview implies that Phil Brook has been challenged by a mixed martial art fighter, the guest tries to be less overt with his disagreement by shifting responsibility and offering justification for his objection.

In addition to the subject, the severity of disagreement also varies according to how much the speaker feels that his or her value has been impeded (Rees-Miller, ibid.). Although it is often necessary to maintain the need to avoid threatening other people's images, a person's desire to protect his or her face might outweigh it and cause the speech act of disagreement to be more direct. For instance, in the seventh sample of the data from Off the Record, the host, Michael Landsberg, seems to feel that his professional identity has been threatened as Phil Brooks, the guest, accuses him of rendering his debut in the Ultimate Fighting Championship a source of amusement. The host, as a result, decides to adopt a more aggravated form of disagreement through using repetition in the form of a question to overtly challenge the addressee's assessment. Analyzing this severe form of disagreement along with a more weakened form, it appears Rees-Miller's explanation is rather plausible when John Cena, the guest in Larry King Now, apparently does not feel any personal imposition from the host's proposition in sample 12 after Larry King discusses the possibility of a reappearance of Hulk Hogan in the World Wrestling Entertainment. Feeling the lack of 
personal impediment, the guest simply disagrees by using humor and implies that he is not completely certain about the host's utterance.

\section{Results and Discussions}

\subsection{The lack of emphasis on disagreement in EFL materials}

The analysis above suggests that non-native students may require abundant pragmalinguistic and sociopragmatic assistance and preparation to adequately express their ideas during highly-charged situations where his or her disagreement could place more immense face-threat on the addressees. Unfortunately, as discussed above, studies show that the focus on disagreement as a speech act is still minimal as global textbooks rarely provide comprehensive explanations on vital elements to achieve pragmatic competence such as the level of formality, the relationship between the interlocutors, or the topic of the speech act (Ren W and Han, ibid.; Vellenga, ibid.). Although the research conducted focuses mainly on EFL materials at the intermediate level, a similar observation on disagreement presented in the current analysis on EFL textbooks from higher levels also reveals a similar alarming trend which may prevent learners from successfully acquiring this important speech act. For instance, in New Total English - Upper-intermediate by Crace \& Acklam (2011), the expressions suggested by the writers for realizing the speech act of disagreement were 'You can't really say that...', 'if you take into account...', 'But then again so is...'. While the first expression appears to possess the speaker's direct intention to disagree, the latter two could be so indirect that learners might not possibly understand that they serve as an opposition to someone's opinion unless they are provided with sufficient context. In the subsequent task, the students are asked to either express agreement or disagreement among their group members about which invention they believe to be the most important. Considering the lack of structure provided by the materials, it is arguable that learners are not fully equipped and ready for such a discussion. Ultimately, they might end up producing expressions of disagreement that are not suitable under other circumstances. Similarly, in an attempt to teach advanced learners how to disagree in the New Headway textbook by Soars \& Soars (2015), formulaic expressions are offered without any elaboration on the situations or relationships between the speakers (see Extract 1). An additional issue with this underrepresentation of disagreement concerns the insufficient pragmatic information (i.e. politeness, culture, or appropriateness); hence, learners who are familiar with such scarcity of contextual information could be in an intensely vulnerable position when they communicate in any actual face-to-face situations regardless of how proficient their language is.

$\begin{array}{ll}\text { I couldn't disagree more. } & \text { Have it your own way. } \\ \text { That's not how I see it. } & \text { You do not! } \\ \text { Let's just agree to disagree. } & \text { I suppose... } \\ \text { I really take offence at that. } & \text { Look who's talking! } \\ \text { I'm sure we can find a happy medium } & \end{array}$

I'm sure we can find a happy medium.

Extract 1. Phrases for Expressing Disagreement in New Headway-Advanced, $4^{\text {th }}$ Edition (Unit 6, p.56)

\section{Suggestions for teaching how to disagree effectively}

The discussion above further highlights the importance of equipping EFL learners with the awareness of both the linguistic and social factors to disagree effectively under various circumstances. To prevent students from both pragmalinguistic and sociopragmatic failure, teachers, as Koike \& Pearson (2005) suggest, can adopt an active role in directing their attention to factors involved in learning speech acts. Subscribing to this belief that the ability to disagree appropriately can be taught, the following tasks, adapted from the principles of developing students' pragmatic awareness and providing opportunities for practicing communication from Kasper (1997), have been prepared to help a class of upper-intermediate Cambodian EFL learners to understand what is needed to realize the speech act without offending the addressee.

Song, P. (2020). Disagreement: a speech act analysis and classroom implications. International Journal of Linguistics, Literature and Culture, 6(6), 24-35. https://doi.org/10.21744/ijllc.v6n6.1009 
Task 1: Collecting samples of disagreement before coming to class

Directions: Because the class is conducted once every week, it is possible to ask the students to spend seven days collecting at least seven to eight pieces of data related to disagreements from any possible sources such as a sitcom, a film, a newspaper, or an in-class interaction. The students are also asked to record important details of the interaction using the data record provided (see Figure 2).

\begin{tabular}{|c|c|c|c|c|c|}
\hline $\begin{array}{l}\text { Information } \\
\text { about } \\
\text { speaker the } \\
\text { person who } \\
\text { disagrees } \\
\begin{array}{l}\text { (age, } \\
\text { relationship with } \\
\text { the addressee) }\end{array} \\
\end{array}$ & $\begin{array}{l}\text { Information } \\
\text { about the } \\
\text { addressee } \\
\text { person who is } \\
\text { objected } \\
\text { (age, sex, } \\
\text { relationship with } \\
\text { the speaker) }\end{array}$ & $\begin{array}{l}\text { Subject of } \\
\text { disagreement } \\
\text { (e.g. food, } \\
\text { politics, } \\
\text { weather...) }\end{array}$ & 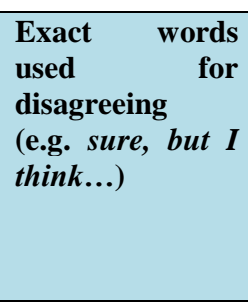 & $\begin{array}{l}\text { Exact words } \\
\text { used for } \\
\text { justifying the } \\
\text { disagreement - } \\
\text { if any } \\
\text { (e.g. Because...) }\end{array}$ & $\begin{array}{l}\text { Context of the } \\
\text { situation } \\
\text { (when and where } \\
\text { the disagreement } \\
\text { happens) }\end{array}$ \\
\hline & & & & & \\
\hline & & & & & \\
\hline & & & & & \\
\hline & & & & & \\
\hline & & & & & \\
\hline & & & & & \\
\hline & & & & & \\
\hline & & & & & \\
\hline
\end{tabular}

Figure 2. Data record

Purposes: This modification of what Kasper (ibid.) calls structured observation allows students to discover how the speech act of disagreement is realized in a more natural setting. Thus, it allows them to become more reflective and alert to the different language uses in various contexts rather than being presented with phrases without a clear explanation about when it is suitable to use such linguistic features. Also, by being an observer of the language themselves, the students might become keener and more motivated in learning the speech act as they are aware that disagreement is an important component for communication in the target language (Tarone \& Yule, 1989).

\section{Task 2: Discussing the data collected}

Directions: In class, the students are asked to work in pairs to discuss the results of the findings in Task 1. To facilitate the discussion, the teacher provides guiding questions like the following:

1) Are there any similarities in your data? If possible, categorize those similarities.

2) Are there any differences in your data? If possible, categorize those similarities.

Purposes: The task is created to connect students' data with the strategies found in the corpus to show that there are various alternatives to achieve the speech act. Furthermore, through the discussion, the learners might become more aware of components, such as the social distance, the topic, and context, which can contribute to the directness level as well as the success of the achievement of the speech act. 
Task 3: Creating contexts for disagreement

Directions: In Task 3, the students create a possible scenario (e.g. the topic, what the addressees might have said, who the interlocutors are, etc.) for each statement (see Figure 3) to show that the utterance is an example of disagreement. The teacher can group the students in pairs to discuss their answers before eliciting responses from the class.

1. Well, it's nice, but I think Angkor Wat is more wonderful.

2. The most reliable person?

3. Yeah, but some people would say that this is the old way of thinking.

4. I don't know why, but the ending is depressing to me.

5. That's ridiculous. It will never happen.

6. Uhm, well, I am not totally convinced about that.

7. Of course, if you enjoy people following you everywhere you go.

8. Pardon me if I am wrong, I think it should be 9am, not $8 \mathrm{am}$.

9. It might be, but adults tend to be more motivated.

10. The idea is good, but I am not sure if it is applicable.

Figure 3. Sentences for analyzing

Purposes: By asking the students to imagine a possible situation for each statement, the teacher could further assist them with the language needed to disagree since the corpus has shown that there are different forms capable of realizing the speech act. As they work to provide a likely context in which the sentence may occur, the learners' attention may also be drawn to crucial factors for sociopragmatic competence such as the participants involved in the speech act, their relationship status, and the topic of the utterance. Also, the students might become more cautious of certain times when the speaker uses off-the-record strategies to disagree (e.g. sentence 7) and focus on the intended illocutionary force beyond the linguistic form.

Task 4: Acting in role plays

Directions: In pairs, the students need to work together to prepare a role-play involving disagreement for each situation provided (see Figure 4). Also, they are asked to discuss the potential adjustment in the topic and linguistic forms of particular variables related to age, status, and setting are altered. The pairs would then be grouped with another couple of students, so they can perform their tasks and deliberate on their ideas. The teacher can ask for a few pairs to act in each situation before discussing with the whole class about the possible topics, linguistic forms, and comments on the alteration required after specific elements have been changed.

Situation 1: In a class of 30 students, the professor (the addressee) said 'It would be wonderful if our students wore uniforms around the campus.'. One of the students (the speaker) disagrees.

- Would there be any adjustment in the way you disagree if (a) the addressee was the speaker's friend (b) if the speaker is another professor (c) both participants were in a park (d) the addressee said 'It's fun going to the beach at night.'

Situation 2: An elder employer (the addressee) to a younger employer (the speaker): 'Whenever I see you, you are either chatting on the phone or playing computer games.'. The speaker disagrees.

- Would there be any adjustment in the way you disagree if (a) the addressee said 'duck tastes better than chicken.' (b) both participants were of a similar age (c) the speaker was older than the employer.

Situation 3: Two best friends are discussing with one another, and one of them said: 'I love winter.'.

- Would there be any adjustment in the way you disagree if (a) both participants were acquaintances (b) the addressee said 'All people should bevegetarians.' (c) the participants were husband and wife (d) the addressee was the speaker's grandfather.

Figure 4. Situations for students' role play

Song, P. (2020). Disagreement: a speech act analysis and classroom implications. International Journal of

Linguistics, Literature and Culture, 6(6), 24-35. https://doi.org/10.21744/ijllc.v6n6.1009 
Purposes: The final activity of the session serves to see how well the students comprehend some of the structures suggested for disagreeing in a less controlled way. Moreover, the role play can also raise students' awareness that people, in some circumstances, tend to justify their disagreement with reasons. As the corpus shows, justification commonly follows disagreement, so it is also worth mentioning to the students that these two speech acts tend to occur together. The question on possible changes according to the topic, relation, and setting of the interaction could provide learners with the idea that these variables are necessary for sociopragmatic competence (Azhari, 2018).

As this is the first time learners are introduced to the speech act of disagreement, a deeper examination of cultural differences in this speech act should be reserved for later discussion. However, the teacher needs to emphasize the fact that cultural values are as vital as other elements discussed in the session. A suggested follow-up task for learners to do at home can be a reflection on all the activities they have done from compiling disagreement samples to acting in role plays. As Martip-kniep (2000) suggests, students' reflections can be a powerful tool for them to evaluate the information they have acquired from the session, and the teacher can also use their reflections to improve any limitation in the tasks given.

\section{Conclusion}

Eslami-Rasekh's (2005), article about encouraging students to be more aware of pragmatics provides some interesting cautionary notes for both teachers and students as she believes that the former needs to be enthusiastic in the field to help their learners become effective observers. Thus, the teachers should also be able to identify the definition of the speech act clearly and collect their sample data to help students understand any potential pragmatic difficulties. However, we should remember that, according to research from LoCastro (2001) and Washburn (2001), some students intentionally refuse to adopt the pragmatic routine of the native speakers of the target language even though they can do so. Therefore, this issue of cross-cultural resistance needs to be handled with care by the teachers to cultivate learner's freedom of choice and their value system while they simultaneously ensure that those learners would not face the risk of being portrayed as tactless or disrespectful nonnative speaker of the target language.

Although the corpus for the present analysis is rather small and requires other instances where the disagreement is derived from people with unequal statuses or other important contexts, the discoveries from this examination of disagreement in two interview settings have given many valuable insights into how to approach this speech act. First, there are various strategies beyond what is typically provided in global EFL textbooks to disagree appropriately under different situations. Also, disagreement does not always happen indirectly since the speaker might also weigh the level of face-threat the addressee's utterance carries and disagree accordingly. Finally, the tasks suggested have been created based on the analysis since it is believed that students need a lot of support from teachers in developing their pragmatic competence of English language norms if they are to become fully-proficient speakers of English.

\section{Conflict of interest statement}

The author declared that she has no competing interests.

Statement of authorship

The author has a responsibility for the conception and design of the study. The author has approved the final article.

\section{Acknowledgments}

I am grateful to two anonymous reviewers for their valuable comments on the earlier version of this paper. 


\section{References}

Angouri, J., \& Locher, M. A. (2012). Theorising disagreement. Journal of Pragmatics, 44(12), 1549-1553. https://doi.org/10.1016/j.pragma.2012.06.011

Austin, J. L. (1962). How to do things with words. Clarendon. Oxford, 2005, 619-650.

Azhari, A. S. (2018). Speech acts of classroom interaction. International journal of linguistics, literature and culture, 4(2), 24-45.

Bardovi-Harlig, K., \& Dörnyei, Z. (1997). Pragmatic awareness and instructed L2 learning: An empirical investigation. In AAAL 1997 Conference, Orlando.

Bardovi-Harlig, K., \& Hartford, B. S. (1990). Congruence in native and nonnative conversations: Status balance in the academic advising session. Language learning, 40(4), 467-501.

Brown, P., Levinson, S. C., \& Levinson, S. C. (1987). Politeness: Some universals in language usage (Vol. 4). Cambridge university press.

Crace, A., \& Acklam, R. (2011). New Total English - Upper-intermediate. Harlow: Pearson Longman.

Eslami-Rasekh, Z. (2005). Raising the pragmatic awareness of language learners. ELT journal, 59(3), 199-208.

Flowerdew, J. (2012). Discourse in English language education. Routledge.

Kakava, C. (2002). Opposition in Modern Greek discourse: cultural and contextual constraints. Journal of pragmatics, 34(10-11), 1537-1568. https://doi.org/10.1016/S0378-2166(02)00075-9

Kasper, G. (1997). The role of pragmatics in language teacher education. Beyond methods: Components of second language teacher education, 113-136.

Koike, D. A., \& Pearson, L. (2005). The effect of instruction and feedback in the development of pragmatic competence. System, 33(3), 481-501. https://doi.org/10.1016/j.system.2005.06.008

Leech, G. N. (1983). Principles of Pragmatics Text. London, NY: Longman.

LoCastro, V. (1986). Yes, I Agree with You, But...: Agreement and Disagreement in Japanese and American English.

LoCastro, V. (2001). Individual differences in second language acquisition: Attitudes, learner subjectivity, and L2 pragmatic norms. System, 29(1), 69-89. https://doi.org/10.1016/S0346-251X(00)00046-4

Malamed, L. H. (2010). How to disagree agreeably. Speech act performance: Theoretical, empirical and methodological issues, 26.

Martin-Kniep, G. O. (2000). Becoming a better teacher: Eight innovations that work. ASCD.

Paltridge, B. (2012). Discourse analysis: An introduction. (pp. 38-61). Bloomsbury Publishing.

Rees-Miller, J. (2000). Power, severity, and context in disagreement. Journal of pragmatics, 32(8), 1087-1111. https://doi.org/10.1016/S0378-2166(99)00088-0

Ren, W., \& Han, Z. (2016). The representation of pragmatic knowledge in recent ELT textbooks. Elt Journal, 70(4), 424-434.

Salsbury, T., \& Bardovi-Harlig, K. (2000). Oppositional talk and the acquisition of modality in L2 English. Social and cognitive factors in second language acquisition, 57, 76.

Soars, J., \& Soars, L. (2015). American Headway: Proven Success Beyond the Classroom. Oxford University Press.

Tarone, E., Yule, G., \& Yule, G. (1989). Focus on the language learner: Approaches to identifying and meeting the needs of second language learners (pp. 34-39). Oxford: Oxford University Press.

Thomas, J. A. (2014). Meaning in interaction: An introduction to pragmatics. Routledge.

Vellenga, H. (2004). Learning Pragmatics from ESL \& EFL Textbooks: How Likely?. Tesl-Ej, 8(2), n2.

Washburn, G. N. (2001). Using Situation Comedies for Pragmatic Language Teaching and Learning. TESOL journal, 10(4), 21-26. 


\title{
Appendix 1:
}

The basic structure of the realization of the speech act of disagreement is as the following.

\author{
Addressee: $\langle\mathrm{P}\rangle$ \\ Speaker: $\langle$ Not $\mathrm{P}\rangle\langle\mathrm{J}\rangle$
}

P: proposition (a statement or utterance made by the addressee)

J: Justification for the speaker's disagreement.

Data set 1: an interview between Michael Landsberg and his guest, Phil Brooks, on Off the Record aired on December 19, 2014. They discussed Phil Brooks' transition from being a professional wrestler at the World Wrestling Entertainment to being a mixed martial art fighter at the Ultimate Fighting Championship.

(1) PB: Sure, yeah. I'll fight the chef. $\langle P\rangle$ I'll fight you. I'll fight anybody.

ML: Well, $<$ Not $P>$ no, you're not gonna fight me.

(2) PB: Yes, $\langle P>$ I have taken a real punch in the face.

ML: But... $<$ Not $P>$ wouldn't you agree that this is different? $<J>$ That then being in the octagon say with the guy who is punching to hurt and it's not part of putting on a show?

(3) ML: $\langle P\rangle$ Nate Diaz has called you out. If they offered you a chance to fight him at any weight. So you're heavier than him you can fight at that. Would you fight a guy with Nate Diaz's experience?

PB: Look. $<$ Not $P>$ This is this is where errr... you know things...things will get said out of context. $\langle$ Not $P\rangle$ I don't think I don't think Nate called me out. $(J)$ I think what Nate did was opinion on the UFC signing me and me fighting in the UFC.

(4) ML: In the case of Bret Hart...I mean Bret Hart felt like he killed his brother. Yet eventually you know Bret went back. $\langle P\rangle$ So I mean quote unquote just business seems to be very powerful.

PB: $\langle$ Not $P>\mathrm{Su}$...re but you know my integrity is pretty powerful as well.

(5) ML: How do you find that that given your public feud with Vince and $\langle P\rangle$ you really called him out about the medical care that they offered their people. Erm I mean what it's like for your wife working for a company...?

PB: See... $<$ Not $P>$ this is this is this is taken out of context. $<$ Not $P>$ I didn't I didn't mean to call anybody out. $\langle J\rangle$ I simply told my story and I told people what happened to me.

(6) PB: $\langle P\rangle$ You have an agenda, so it's okay.

ML: Well, $\langle$ Not $P>$ I don't have an agenda but what am I gonna ask you about UFC? $\langle J\rangle$ You're not a UFC fighter. $\langle J\rangle$ You don't have a fight schedule.

(7) PB: You produced an entire segment prior to me coming on err... $<P>$ making a joke of the situation and I understand that and I appreciate your point of view.

ML: Well, I mean, <Not $P>$ making a joke of it?

(8) PB: $\langle P\rangle$ Your demeanor off camera is one hundred percent different than what it is when you know you're being recorded and you're interviewing me. And it's funny to me.

ML: Okay, $\langle$ Not $P\rangle$ so I am interested in that. $\langle J\rangle$ Because I have never heard that before. 
Data set 2: an interview between Larry King and his guest, John Cena, on Larry King Now aired on February 18,

2014. They discussed the World Wrestling Entertainment and the possible return of a former WWE wrestler, Hulk Hogan.

(9) LK: $\langle P\rangle$ You're considered the face of the WWE. Are you aware of that?

JC: Uh... $<$ Not $P>$ we...we have a very strong brand and I think um... $\langle$ Not $P>\mathrm{I}$ would look at it like a baseball team. $\langle$ Not $P>$ There's a bunch of players on that team and certain players may be more popular than others, but you need to feel the team to win.

(10) LK: $\langle P\rangle$ Now the crowd know good beats evil.

JC: Uhh, $\langle$ Not $P>$ depends on who you ask. $\langle J>$ Like I'm supposed to be a good guy in some realm but some audience don't really like me.

(11) LK: $\langle P\rangle$ You're a goody-two-shoes.

JC: $\langle$ Not $P\rangle$ Not a goody-two-shoes. $\langle$ Not $P\rangle$ Trust me if you get me pissed off, I'll make you pay for it. $\langle J>$ But err...it's one I have ummm... I have a value set that I am proud to display on television.

(12) LK: $\langle P\rangle$ February $24^{\text {th }}$ is also the day that Hulk Hogan, 97 years old (laugh), returns to the WWE. How did this come about?

JC: I've err heard about this. $\langle$ Not $P>$ I will I will believe it when I see it. I am not sure. (Laugh) I am not sure what's going on. $\langle J\rangle$ I just know we've got a pretty big event in the first week of April. $\langle$ Not $P>$ You never can tell with the Hulkster.

Song, P. (2020). Disagreement: a speech act analysis and classroom implications. International Journal of 